\title{
The clinical significance of aldosterone synthase deficiency: report of a novel mutation in the CYP11B2 gene
}

\author{
Elaine Hui ${ }^{1}$, Matthew CW Yeung ${ }^{2}$, Pik To Cheung ${ }^{3}$, Elaine Kwan ${ }^{3}$, Louis Low ${ }^{3}$, Kathryn CB Tan ${ }^{1}$, Karen SL Lam \\ and Angel OK Chan ${ }^{2 *}$
}

\begin{abstract}
Background: Aldosterone synthase (CYP11B2) deficiency is a rare autosomal recessive disorder, usually presenting with severe salt-wasting in infancy or stress-induced hyperkalaemia and postural hypotension in adulthood. Neonatal screening for congenital adrenal hyperplasia, another cause of salt wasting, using 17-hydroxyprogesterone measurement would fail to detect aldosterone synthase deficiency, a diagnosis which may be missed until the patient presents with salt-wasting crisis. Due to this potential life-threatening risk, comprehensive hormonal investigation followed by genetic confirmation for suspected patients would facilitate clinical management of the patient and assessment of the genetic implication in their offspring.

Case presentation: We describe a 33-year old Chinese man who presented in infancy with life-threatening hyponatraemia and failure to thrive, but remained asymptomatic on fludrocortisone since. Chromosomal analysis confirmed a normal male karyotype of 46, XY. Plasma steroid profile showed high plasma renin activity, low aldosterone level, and elevated 18-hydroxycorticosterone, compatible with type 2 aldosterone synthase deficiency. The patient was heterozygous for a novel CYP11B2 mutation: c.977C > A (p.Thr326Lys) in exon 3. He also carried a heterozygous mutation c.523_525delAAG (p.Lys175del) in exon 6, a known pathogenic mutation causing aldosterone synthase deficiency. Sequencing of CYP11B2 in his parents demonstrated that the mother was heterozygous for c.977C > A, and the father was heterozygous for c.523_525delAAG.
\end{abstract}

Conclusion: Although a rare cause of hyperreninaemic hypoaldosteronism, aldosterone synthase deficiency should be suspected and the diagnosis sought in patients who present with life-threatening salt-wasting in infancy, as it has a good long-term prognosis when adequate fludrocortisone replacement is instituted. To our knowledge, this is the first Chinese patient in which the molecular basis of aldosterone synthase deficiency has been identified.

Keywords: Aldosterone synthase deficiency, Salt-wasting, Hypoaldosteronism

\section{Background}

Aldosterone is the main mineralocorticoid hormone in humans that regulates sodium excretion and intravascular volume. It acts via distal renal tubules and cortical collecting ducts by increasing sodium reabsorption from and potassium excretion into the urine. It is synthesized by aldosterone synthase (CYP11B2), an enzyme encoded by CYP11B2, expression of which is almost entirely confined

\footnotetext{
* Correspondence: cok436@ha.org.hk

${ }^{2}$ Department of Pathology, The University of Hong Kong, Queen Mary

Hospital, Pokfulam Road, Pokfulam, Hong Kong

Full list of author information is available at the end of the article
}

to the adrenal cortex and exclusively in the zona glomerulosa layer. Aldosterone synthase is a cytochrome P450 enzyme that catalyses the final 3 steps of aldosterone biosynthesis: first by the hydroxylation of deoxycorticosterone (DOC) at position $11 \beta$ to form corticosterone (B), then the hydroxylation at position 18 to form 18hydroxycorticosterone (18OHB), and lastly the oxidation at position 18 to aldosterone [1]. Isolated deficiencies of aldosterone biosynthesis are caused by inactivating mutations in the CYP11B2 gene [2,3]. Aldosterone deficiency leads to excessive sodium excretion and potassium retention, resulting in hyponatraemia, hyperkalaemia, and 
metabolic acidosis. Cases of aldosterone synthase deficiency (ASD) have been identified in Iranian Jews, Europeans and North Americans [4]. In Asians, it has been reported in Thai, Japanese and Indian individuals $[5,6]$. To our knowledge, there has been no report of Chinese cases with confirmed genetic analysis. Here, we describe a case of aldosterone synthase deficiency in a Chinese man and results of CYP11B2 analysis in the patient and his family.

\section{Case presentation}

\section{Case report}

The index patient, at the time of this report aged 33 years old, was delivered normally at term with a birth weight of $3.1 \mathrm{~kg}$. He had repeated vomiting with poor feeding and failure to thrive at 5 weeks of age. He was found to have hyponatraemia and was started on cortisone acetate $2.5 \mathrm{mg}$ three times daily and fludrocortisone $50 \mu \mathrm{g}$ daily on the presumptive diagnosis of congenital adrenal hyperplasia. He had normal male phenotype and chromosomal analysis confirmed a normal male karyotype of $46, \mathrm{XY}$. He was evaluated with supervised treatment withdrawal by 6 months old. 24-hour urinary ketosteroid was normal but plasma renin activity was high and aldosterone was low, suggestive of hypoaldosteronism. Cortisone acetate was subsequently stopped. Plasma steroid profiling, which was performed after withholding therapy for a week at the age of 14.5 years old, gave characteristic findings of type 2 ASD (Table 1). Developmental milestones, electrolytes and blood pressure were normal while on fludrocortisone $100 \mu \mathrm{g}$ daily. Both his unrelated parents and his older brother were phenotypically normal.

\section{Genetic analysis}

During family planning, genetic analysis was performed to ascertain the diagnosis at the age of 33 years. Blood samples were obtained and genomic DNA extracted from the patient, his brother and both non-consanguineous parents with informed consent. The nine coding exons and flanking intronic regions (15 bp) of the CYP11B2 gene were amplified by polymerase chain reaction on the patient's genomic DNA, followed by direct DNA sequencing using primers and conditions as previously described [5]. Targeted mutational analysis was also performed on both parents and his brother's genomic DNA. The patient and family members' DNA sequences were compared to NCBI Reference Sequences, NG_008374.1, NM_000498.3 and NP_000489.3. The affected patient carried a novel heterozygous missense mutation: c.977C > A (p.Thr326Lys) in exon 3 (Figure 1), which has not previously been reported. He also carried a heterozygous mutation c.523_525delAAG (p.Lys175del) in exon 6, a known pathogenic frameshift mutation causing ASD [7]. Sequencing of CYP11B2 in the parents demonstrated that the mother was heterozygous
Table 1 Plasma steroid profile of the patient

\begin{tabular}{|c|c|c|}
\hline & Basal (nmol/L) & $\begin{array}{l}\text { Post-ACTH stimulation } \\
\text { (nmol/L) }\end{array}$ \\
\hline Aldosterone & $0.166(0.39-2.44)$ & $0.19(0.01-0.55)$ \\
\hline $\begin{array}{l}\text { 18-OH-Corticosterone } \\
\text { (18-OHB) }\end{array}$ & $7.06(0.56-1.46)$ & $12.1(0.83-5.5)$ \\
\hline Corticosterone & $44.4(0.14-14.23)$ & $151.8(34.0-208.4)$ \\
\hline $\begin{array}{l}\text { 18-OH- } \\
\text { deoxycorticosterone }\end{array}$ & $1.64(0.13-0.72)$ & $5.28(0.58-6.1)$ \\
\hline Deoxycorticosterone & $0.57(0.09-0.57)$ & $2.36(0.27-1.35)$ \\
\hline Progesterone & $1.94(0.095-3.15)$ & $2.96(0.52-2.55)$ \\
\hline $\begin{array}{l}17- \\
\text { hydroxyprogesterone }\end{array}$ & $3.09(0.24-4.93)$ & $15.2(1.88-10.96)$ \\
\hline 11-Deoxycortisol & $2.22(0.15-2.58)$ & $14.5(1.36-9.44)$ \\
\hline Cortisol & $274.3(59.9-480)$ & $721.5(317.3-979.3)$ \\
\hline Cortisone & $161.2(6.37-123.6)$ & $59.9(34.8-79.7)$ \\
\hline \multicolumn{3}{|l|}{ Ratio } \\
\hline $\mathrm{B} / 18-\mathrm{OHB}$ & 6 & 12 \\
\hline 18-OHB/ aldo & 43 & 63 \\
\hline
\end{tabular}

Plasma steroid profile showed low aldosterone level, elevated 18-hydroxycorticosterone (18-OHB), low corticosterone/18-OHB and high 18-OHB/aldosterone ratios, compatible with type 2 aldosterone synthase deficiency.

for c.977C > A (p.Thr326Lys) and the father was heterozygous for c.523_525delAAG (p.Lys175del). Neither mutation was detected in the patient's brother.

\section{Discussion}

We describe a Chinese man who presented with severe salt-wasting in infancy and hyperreninaemic hypoaldosteronism, and in whom genetic analysis confirmed aldosterone synthase deficiency. He remained clinically well in adulthood with normal electrolytes and blood pressure whilst on fludrocortisone.

Inadequate aldosterone production results in decreased renal sodium reabsorption and potassium excretion in ASD. Clinical severity varies, with the most severe forms presenting in infancy. Affected infants usually develop vomiting, dehydration, hypovolaemia, and failure to thrive at a few days to weeks following delivery [8]. However, saltlosing crisis in isolated ASD is usually indistinguishable clinically from other forms of defective steroid biosynthesis, such as 21-hydroxylase deficiency in congenital adrenal hyperplasia. Therefore, life-threatening saltwasting in affected infants is usually treated initially with both hydrocortisone and fludrocortisone pending steroid hormone analysis [9]. Phenotypically, infants with ASD have normal external genitalia [5]. Hydrocortisone can be withdrawn once characteristic steroid profile or genetic mutations of CYP11B2 gene are confirmed. A typical biochemical profile of this disorder includes hyponatraemia, hyperkalaemia, raised plasma 


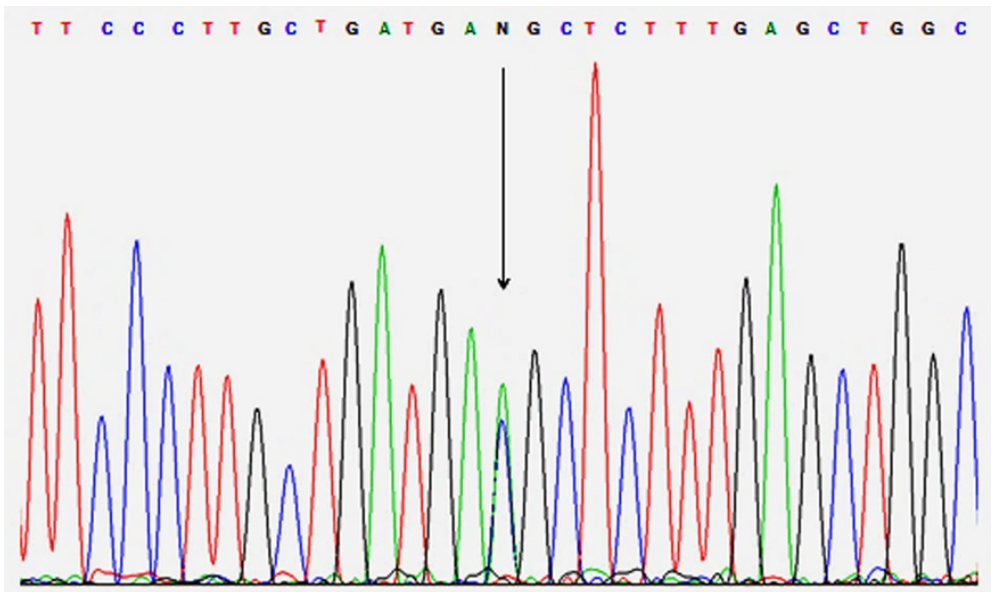

Figure 1 Electropherogram of segment of CYP11B2 showing the heterozygous c.977C > A mutation. The mutation site is denoted by the letter $\mathrm{N}$ and is indicated by an arrow.

renin activity, undetectable or low aldosterone level, and normal or elevated cortisol levels.

Aldosterone synthase deficiency has been classified based on biochemical phenotypes: in type $1 \mathrm{ASD}$, the enzymatic CYP11B2 activity is completely abolished. Affected individuals have low to normal levels of $18 \mathrm{OHB}$, and undetectable to low levels of plasma aldosterone or its urinary metabolite, tetrahydroaldosterone [10]. In type 2 deficiency, the mutations in the CYP11B2 gene only decrease 18-hydroxylase and 18-oxidase activities, but not $11 \beta$-hydroxylase activity. It differs from type 1 in that 18-OHB levels are markedly elevated, whilst plasma aldosterone levels and urinary tetrahydroaldosterone are low [7]. However, it is now recognised that these biochemical phenotypes have clinical, hormonal and genotypic overlapping features [11] and that type 1 and type 2 ASD would be better considered a continuous spectrum of the same disease [5].

As clinical severity gradually improves with age, affected adults are usually asymptomatic despite no mineralocorticoid therapy $[5,12]$. However, termination of mineralocorticoid may lead to postural hypotension and hyperkalaemia when triggered by stress due to dehydration or reduced salt intake in some affected adults [12]. Generalised weakness with marked hyperkalaemia and dehydration has been reported as the first presentation in a middle-aged man after concurrent institution of indapamide for hypertension and bowel preparation for barium enema. Interestingly, further questioning revealed a past history of vomiting and failure to thrive in early infancy that resolved without any mineralocorticoid replacement [13]. Therefore, detailed childhood history would be a helpful clue in suspected ASD case presenting in adulthood. Possible mechanisms for reduced clinical severity of ASD with advancing age include increasing sensitivity to mineralocorticoid action and sodium intake with age. It has been shown that mineralocorticoid receptor expression in human kidneys begins with low levels in late gestation and rises progressively after birth [14]. Another potential mechanism is age-dependent impaired 11ß-hydroxysteroid dehydrogenase type 2 activity, leading to greater cortisol availability for the mineralocorticoid receptor with age [15].

Neonatal screening for CAH using 17-hydroxyprogesterone measurement would fail to detect ASD, as infants with ASD usually have normal [12] or slightly elevated basal and stimulated 17-hydroxyprogesterone [9]. The diagnosis of ASD may therefore be missed until the patient presents with salt-wasting crisis. Therefore, comprehensive hormonal investigation followed by genetic confirmation for suspected adults and their respective partners would be useful to assess the genetic implication in their offspring and to minimize the potential life-threatening risk.

Compound heterozygosity has been reported when phenotypically unaffected parents contribute to each allele with a heterozygous mutation, rendering phenotypes of ASD type 1 in the affected offspring $[6,10]$. Our current case inherited one of the heterozygous mutations c.977C > A (p.Thr326Lys) maternally, and the other c.523_525delAAG (p.Lys175del) paternally. The unaffected parents are heterozygous for their respective mutations, in accordance with an autosomal recessive inheritance. In silico protein function prediction using PolyPhen-2 and Align GVGD both predict the novel missense variant c.977C > A (p.Thr326Lys) to be damaging. Multiple sequence alignment of the CYP11B2 gene also showed that the threonine residue is highly conserved across multiple mammal species (Table 2). The threonine residue in codon 326 is located in the Ihelix of CYP11B2 protein (Figure 2). A previous study mapping the amino acid difference between CYP11B2 
Table 2 Multiple sequence alignment of a segment of the CYP11B2 gene

\begin{tabular}{ll}
\hline Homo sapiens & GSVDTTAFPLLMTLFELARNPDV \\
Canis lupus & GSVDTTAYPLWMTLFELARNPDV \\
Mus musculus & GSVDTTAIPLVMTLFELARNPDV \\
Macaca mulatta & GSVDTTAFPLLMTLFELARNPDV \\
Rattus norvegicus & GSVDTTAIPLVMTLFELARNPDV \\
\hline
\end{tabular}

Codon 326 of the CYP11B2 gene in homo sapiens and the corresponding codon in other species are in bold phase. The threonine residue at codon 326 (in bold) is highly conserved across different mammal species.

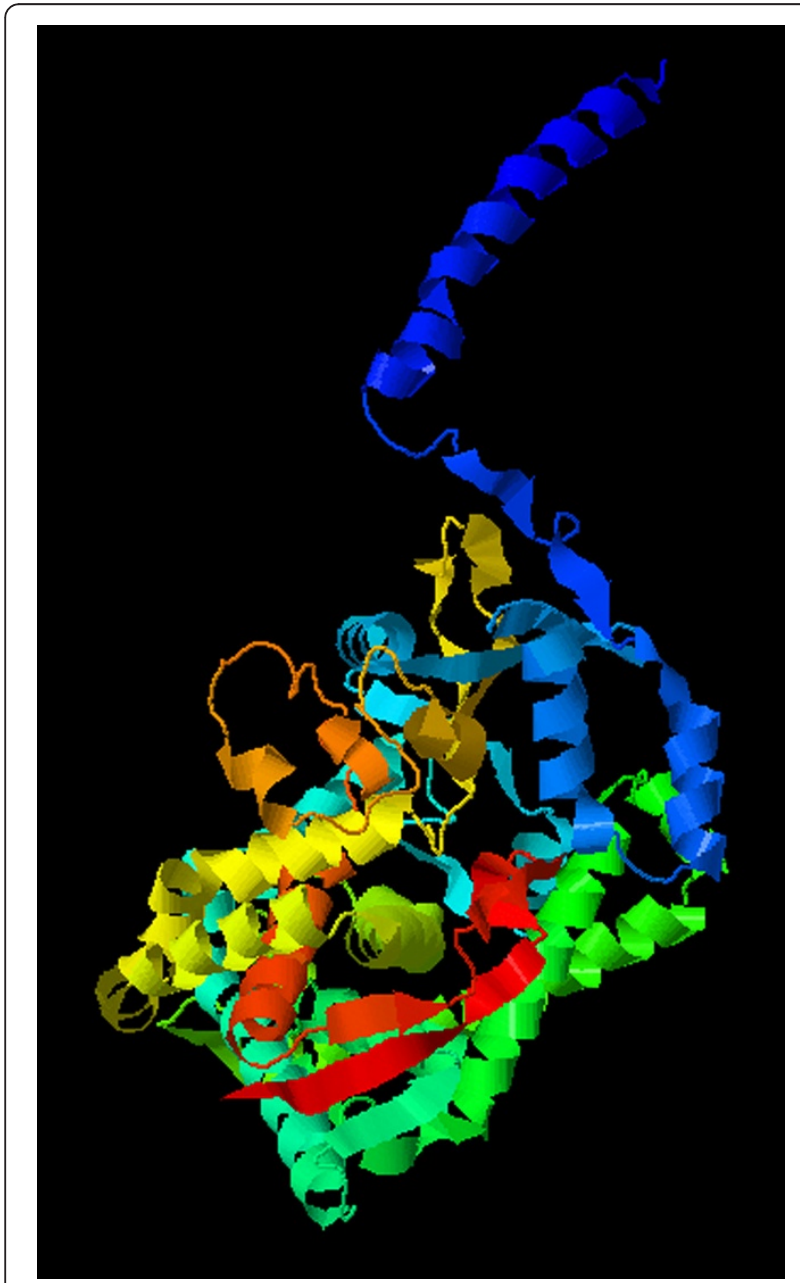

Figure 2 3-D model of the CYP11B2 mutant with the novel missense $\mathbf{c . 9 7 7 C}>\mathrm{A}$ mutation. The threonine residue in codon 326 is located in the I-helix of CYP11B2 protein, which is implicated in 18-hydroxylation/oxidation due to the clusters of CYP11B2 isoform-specific residues in that region. In particular, the alanine residue in position 320 is required for methyloxidase reaction and the p.Thr318Met in the I-helix is a known deleterious mutation causing aldosterone synthase deficiency. This structural information and functional correlation suggest that the I-helix region, where the novel variant c.977C > A (p.Thr326Lys) is located, is important for the enzyme activity of CYP11B2. and $C Y P 11 B 1$ showed that $C Y P 11 B 2$ isoform-specific residues are clustered around the $\mathrm{H}$-helix and in the Ihelix and are essential for 18-hydroxylation/oxidation [16]. In particular, the alanine residue in position 320 in $C Y P 11 B 2$ is required for methyloxidase reaction. Also, p.Thr318Met in the I-helix is a known deleterious mutation causing aldosterone synthase deficiency [11]. This structural information and functional correlation suggest that the I-helix region, where the novel variant c.977C > A (p.Thr326Lys) is located, is important for enzyme activity of CYP11B2. Taking all the aforementioned factors into consideration, the variant c.977C > A (p.Thr326Lys) is likely to be pathogenic, in keeping with our case.

Homozygous p.Lys175del (previously described as homozygous deletion of codon 173 before the use of the latest HGVS nomenclature) has been reported in a girl presenting with salt-wasting during infancy [7]. CYP11B2 is polymorphic at this position, encoding arginine or lysine. Amino acid residue 173 is positioned in $\alpha$-helix D, and the secondary structure of aldosterone synthase was presumed to be altered by the single amino acid deletion. Indeed, using fission yeast system, Tin et al. demonstrated that the deletion mutation at codon 173 displayed markedly reduced $11-\beta$-hydroxylation activity (16.3\%), and no 18-hydroxylation and 18-oxidation activities [17].

\section{Conclusion}

Aldosterone synthase deficiency is a rare cause of hyperreninaemic hypoaldosteronism and its genetic and molecular basis is more heterogeneous than previously described. It should be suspected in infants without virilisation presenting with salt-wasting or in adults presenting with stress-induced hyperkalaemia and a history of failure to thrive in childhood. Our case illustrates the clinical significance to recognize this condition as it has a good long-term prognosis when adequate fludrocortisone replacement is instituted.

\section{Consent}

Written informed consent was obtained by the patient for the publication of this case report and any accompanying images. A copy of the written consent is available for review by the Editor of this journal.

\section{Competing interests}

The authors declare that they have no competing interests.

\section{Authors' contributions}

$\mathrm{EH}$ and MY drafted the manuscript. PTC, EK, LL, MY and AC performed the biochemical and genetic analysis. $K T, K L$ and $A C$ revised the manuscript critically. All authors read and approved the final manuscript.

Acknowledgement

We thank the patient and his family for their support. 


\section{Author details}

'Department of Medicine, The University of Hong Kong, Queen Mary Hospital, Pokfulam Road, Pokfulam, Hong Kong. 'Department of Pathology, The University of Hong Kong, Queen Mary Hospital, Pokfulam Road, Pokfulam, Hong Kong. '3epartment of Pediatrics and Adolescent Medicine, The University of Hong Kong, Queen Mary Hospital, Pokfulam Road, Pokfulam, Hong Kong.

Received: 27 January 2014 Accepted: 31 March 2014

Published: 3 April 2014

\section{Reference}

1. Lisurek M, Bernhardt R: Modulation of aldosterone and cortisol synthesis on the molecular level. Mol Cell Endocrinol 2004, 215:149-159.

2. Pascoe L, Curnow KM, Slutsker L, Rosler A, White PC: Mutations in the human CYP11B2 (aldosterone synthase) gene causing corticosterone methyloxidase II deficiency. Proc Natl Acad Sci U S A 1992, 89:4996-5000.

3. Portrat-Doyen S, Tourniaire J, Richard O, Mulatero P, Aupetit-Faisant B, Curnow KM, Pascoe L, Morel Y: Isolated aldosterone synthase deficiency caused by simultaneous E198D and V386A mutations in the CYP11B2 gene. J Clin Endocrinol Metab 1998, 83:4156-4161.

4. White PC: Aldosterone synthase deficiency and related disorders. Mol Cell Endocrinol 2004, 217:81-87.

5. Klomchan T, Supornsilchai V, Wacharasindhu S, Shotelersuk V, Sahakitrungruang T: Novel CYP11B2 mutation causing aldosterone synthase (P450c11AS) deficiency. Eur J Pediatr 2012, 171:1559-1562.

6. Kondo E, Nakamura A, Homma K, Hasegawa T, Yamaguchi T, Narugami M, Hattori T, Aoyagi H, Ishizu K, Tajima T: Two novel mutations of the CYP11B2 gene in a Japanese patient with aldosterone deficiency type 1. Endocr J 2013, 60:51-55.

7. Peter M, Dubuis JM, Sippell WG: Disorders of the aldosterone synthase and steroid 11 beta-hydroxylase deficiencies. Horm Res 1999, 51:211-222.

8. Ulick S, Wang JZ, Morton DH: The biochemical phenotypes of two inborn errors in the biosynthesis of aldosterone. J Clin Endocrinol Metab 1992, 74:1415-1420.

9. Wasniewska M, De LF, Valenzise M, Lombardo F, De LF: Aldosterone synthase deficiency type I with no documented homozygous mutations in the CYP11B2 gene. Eur J Endocrinol 2001, 144:59-62.

10. Nguyen HH, Hannemann F, Hartmann MF, Malunowicz EM, Wudy SA, Bernhardt R: Five novel mutations in CYP11B2 gene detected in patients with aldosterone synthase deficiency type I: functional characterization and structural analyses. Mol Genet Metab 2010, 100:357-364.

11. Zhang G, Rodriguez H, Fardella CE, Harris DA, Miller WL: Mutation T318M in the CYP11B2 gene encoding P450c11AS (aldosterone synthase) causes corticosterone methyl oxidase II deficiency. Am J Hum Genet 1995, 57:1037-1043.

12. Lovas K, McFarlane I, Nguyen HH, Curran S, Schwabe J, Halsall D, Bernhardt $R$, Wallace AM, Chatterjee VK: A novel CYP11B2 gene mutation in an Asian family with aldosterone synthase deficiency. J Clin Endocrinol Metab 2009, 94:914-919.

13. Kayes-Wandover KM, Schindler RE, Taylor HC, White PC: Type 1 aldosterone synthase deficiency presenting in a middle-aged man. J Clin Endocrinol Metab 2001, 86:1008-1012.

14. Martinerie $L$, Viengchareun $S$, Delezoide AL, Jaubert F, Sinico M, Prevot $S$, Boileau P, Meduri G, Lombes M: Low renal mineralocorticoid receptor expression at birth contributes to partial aldosterone resistance in neonates. Endocrinology 2009, 150:4414-4424.

15. Henschkowski J, Stuck AE, Frey BM, Gillmann G, Dick B, Frey FJ, Mohaupt MG: Age-dependent decrease in 11 beta-hydroxysteroid dehydrogenase type 2 (11 beta-HSD2) activity in hypertensive patients. Am J Hypertens 2008, 21:644-649.
16. Strushkevich N, Gilep AA, Shen L, Arrowsmith CH, Edwards AM, Usanov SA, Park HW: Structural insights into aldosterone synthase substrate specificity and targeted inhibition. Mol Endocrinol 2013, 27:315-324.

17. Tin MK, Hakki T, Bernhardt R: Fission yeast Schizosaccharomyces pombe as a new system for the investigation of corticosterone methyloxidase deficiency-causing mutations. J Steroid Biochem Mol Biol 2011, 124:31-37.

doi:10.1186/1472-6823-14-29

Cite this article as: Hui et al.: The clinical significance of aldosterone synthase deficiency: report of a novel mutation in the CYP11B2 gene. BMC Endocrine Disorders 2014 14:29.

\section{Submit your next manuscript to BioMed Central and take full advantage of:}

- Convenient online submission

- Thorough peer review

- No space constraints or color figure charges

- Immediate publication on acceptance

- Inclusion in PubMed, CAS, Scopus and Google Scholar

- Research which is freely available for redistribution

Submit your manuscript at www.biomedcentral.com/submit
C Biomed Central 